\title{
Study of the influence of chemical anti-icing materials on frost heaving of the roadbed soils
}

\author{
A Y Velsovskij ${ }^{1, *}, V A$ Shorin $^{1}$, T.R. Akhmetov ${ }^{2}$ \\ ${ }^{1}$ Department of Highways, Vologda State University, Lenina ul. 15, 160000, Russia \\ ${ }^{2}$ Kazan State Power Engineering University, str. Krasnoselskaya, 51, 420066, Kazan, Russia
}

\begin{abstract}
This work examines the influence of chemical anti-icing materials on the frost resistance of the road pavement. Methods and technologies for introducing salt additives into the soil are considered. The preparation of soil with salt additives for testing for frost heaving is described. The kinetics of frost heaving processes of the reference soil sample and soil treated with salt additives was investigated. The influence of type and concentration of the salt additive on the degree of frost heaving of soils was investigated. The negative impact of chemical anti-icing additives on the indicators of frost heaving of soils, especially with uneven salinity, was registered.
\end{abstract}

\section{Introduction}

Nowadays, chemical anti-icing materials in the form of sand-salt mixtures, brines and pure chemical reagents are widely used during construction of buildings and road facilities [1-6]. Studies on their applications are most often devoted to the lowering of the freezing point, and to examination of their impact on the environment. But the technical literature doesn't consider any information about their influence on the heaving properties of roadbed soils. Further we describe some issues on saline soils that are of interest now:

- The use of artificial soil salinization as an antiheaving measure in foundation construction;

- The use of artificial salinization for the complex performance of earthworks in winter (development, transportation and laying with soil compaction);

- Study of characteristics of saline soil (including the frozen one) in natural occurrence and their distribution.

The eutectic solutions of sodium chloride, magnesium and calcium are used for soil salinization with freezing points equal to $-21.2,-33.6$ and $-55{ }^{\circ} \mathrm{C}$, respectively. In addition to lowering the freezing point, chloride salts have a significant influence on reduction of heaving. This approach is widely used in foundation engineering. For salinization, both crystalline anhydrous salt and saline solutions are usually used. The latter are not recommended for use in highly moist soils, in order to avoid leaching of these salts from the soil.

With local soil salinization, diffusion of salts occurs from an area of higher concentration to an area of lower concentration. Some time after salinization, the concentration of soil solution decreases within the local salinization area. The rate of penetration of water-soluble salts into the soil can be very different. According to the Pechora Scientific Research Institute, diffusion of salts into thawed cohesive soils occurs with a speed of $2-3 \mathrm{~cm}$ for 10 days, and it is two times slower when diffusing into a frozen soil.

As established by S.B. Ukhov [7], during loam filling in layers of $30 \mathrm{~cm}$ and its layer-by-layer salinization with sodium chloride, the resulting salinization of loam will be almost uniform in 70-80 days. In frozen loam at temperatures from -1.4 to $-4.8^{\circ} \mathrm{C}$, uniform salinity will be achieved in 80-100 days.

Studies on the influence of anti-icing additives on the environment have shown that the use of a sand-salt mixture and brines leads to the accumulation of chemical elements and salts in soils. Their concentration changes with time.

The disadvantages of the soil salinization method also include an increase in the frost hazard of the soil during its desalination, accelerated corrosion of metal structures, and the destruction of soil-bitumen coatings in some cases.

The aim of this work is to study the influence of chemical anti-icing materials on frost heaving of the roadbed soils.

\section{Materials and methods}

Experimental studies aimed at assessing the influence of anti-icing chloride additives used in highways on frost heaving of the roadbed soils included the following stages:

1. Assessing the degree of salinity of the roadbed soil on the road section with the use of anti-icing additives;

2. Determination of heaving properties of soils of the selected samples;

3. Determination of the influence of salinity on the heaving properties of artificially saline soils.

* Corresponding author: v2u@yandex.ru 
For the first stage, the object of research was the motor road of the IIIrd category of regional significance in the Vologda region, on which natural salt brine has been used as an anti-icing additive for more than 10 years.

On the selected section of the road, soil samples of the roadbed were taken from a depth of 1.8-2.3 $\mathrm{m}$ at three sections located at a distance of 1-1.5 km. According to the Russian State Standard GOST 251002011 [8], this soil was classified as tough-plastic light silty loam. Laboratory tests have shown that these samples had the following salinities: $0.07 \%$ for sample No. $1 ; 0.02 \%$ for sample No. 2; $0.06 \%$ for sample No. 3 . Sample No. 3 was taken for further research.

The second stage of study included testing for frost heaving of three samplings made from sample No. 3, as well as the same soil after its desalinization.

Soil desalinization included the following operations:

- Filling with water (in a ratio of 1:10) of soil prepared for desalinization and mixing it until a suspension is formed;

- Curing the suspension until the complete precipitation of mineral particles into the sediment, draining the settled water;

- Drying the sediment (salted soil), thorough mixing of the samples and preparation for testing for frost heaving.

Testing of soil for frost heaving was carried out on setups produces by the Vologda State University [9-14]. The schematic diagram of a device for testing soil samples for frost heaving is shown in Fig. 1.

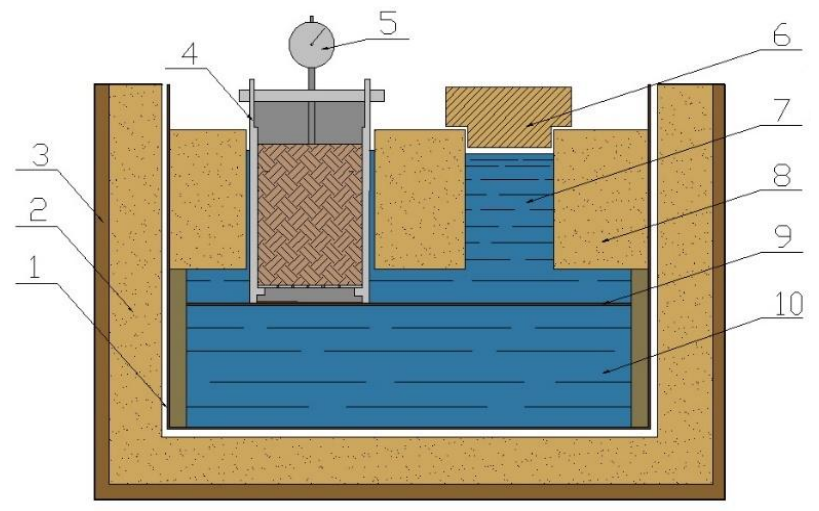

Fig. 1. Schematic diagram of a device for testing soil samples for frost heaving: 1 - reservoir; 2 - thermal insulation; 3 - body; 4 - sample form; 5 - indicator; 6 - plug; 7 - internal reservoir; 8 - cover plate; 9 - lattice; 10 - water.

Unlike the known analogues, the setup uses the principle of communicating vessels, which provides freezing of samples similarly to freezing of watersaturated soil under natural conditions, when the freezing boundary is near the groundwater horizon. This difference allows obtaining more accurate results. The novelty of the setup design is confirmed by the patent for an invention [15].

A general view of the prototype setup is shown in Fig. 2. The installation allows to conduct laboratory tests in accordance with the Russian State Standard GOST
28622-2012 and is characterized by the following technical data:

- The amount of the soil samples being tested is 3-5;

- The testing time during one cycle of frozing is 5-7 days depending on the soil type;

- The setup dimensions are $800 \times 760 \times 1940 \mathrm{~mm}$;

- The setup mass is $140 \mathrm{~kg}$.

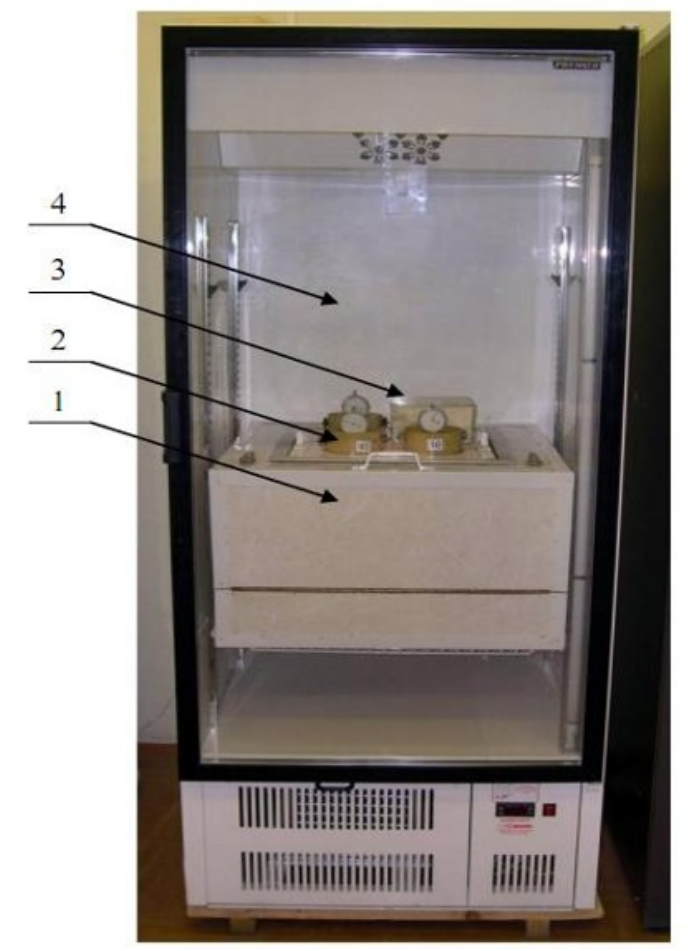

Fig. 2. General view of the installation: 1 - device for testing samples; 2 - test samples; 3 - plug; 4 - refrigerator.

\section{Results and Discussion}

The results of testing the heaving properties of soils of the selected samples are presented in the plots of frost heaving deformation versus time. These plots were constructed for three soil samples from a selected sampling (Fig. 3) and for the desalinated soil of this sampling (Fig. 4). The right scale shows the relative deformation of frost heaving for the stage of complete freezing of the sample and the classification of the degree of frost heaving according to GOST 25100-2011 [8]. These data show that after soil desalinization, its heaving properties improve. Thus, the average value of the relative deformation more than doubled, and the degree of frost heaving from moderately swollen increased to excessively swollen. 


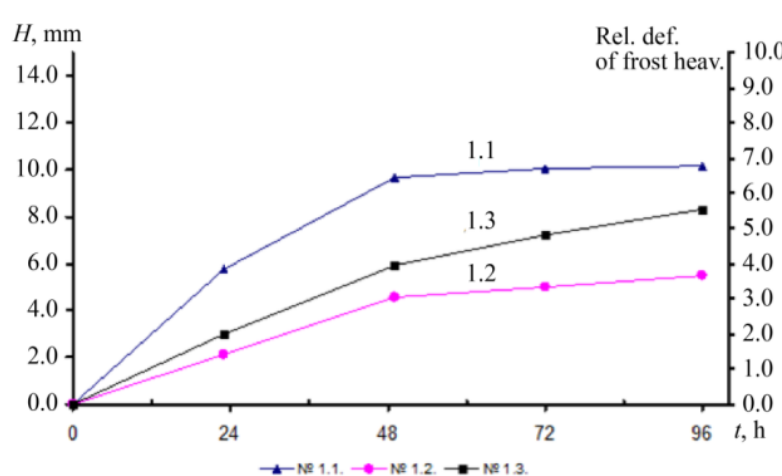

Fig. 3. The relationship between deformation of frost heaving and time for the selected soil samples.

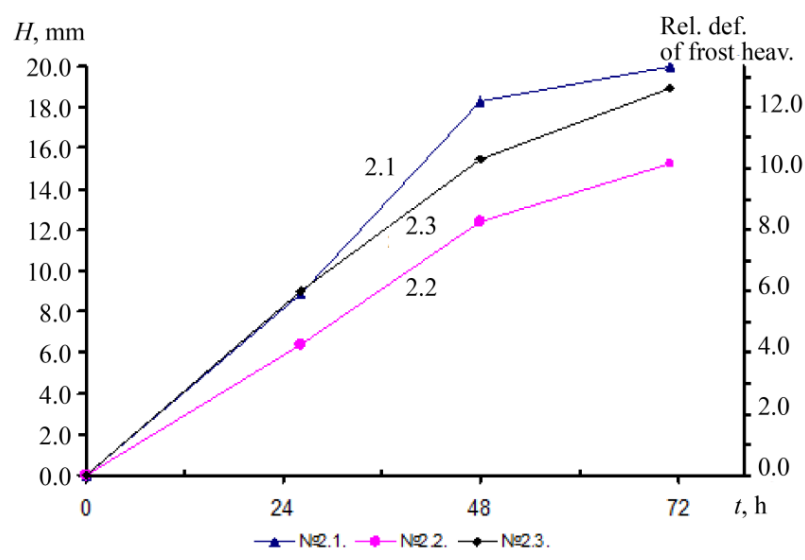

Fig. 4. The relationship between deformation of frost heaving and time for the desalinated soil.

The third stage of the study included the preparation of two types (clay and sandy) of artificially salinizated soils and testing them for frost heaving. These soils were classified as silty sandy loam and fine sand. For soil salinization, sodium chloride salt was used.

Artificial soil salinization included the following operations:

- Preparation of the soil mass necessary for the production of samples in air-dry state with violation of secondary structural bonds;

- Preparation of brines of sodium chloride salt, the concentrations of which were selected so that when poured into the soil, its concentration would be $0.075 \%$ and $0.15 \%$, respectively. The amount of solution introduced into the soil was taken so that the moisture content was optimal;

- Adding solutions to the soil and mixing the soil until uniform moisture content, then keeping in a desiccator. The soil prepared in this way was used to prepare the samples.

Two samples of non-saline and saline soil were prepared.

The plots showing the growth of frost heaving deformation over time for non-saline sandy loam soil and for a soil with a salinity of $0.075 \%$ are presented in Fig. 5.

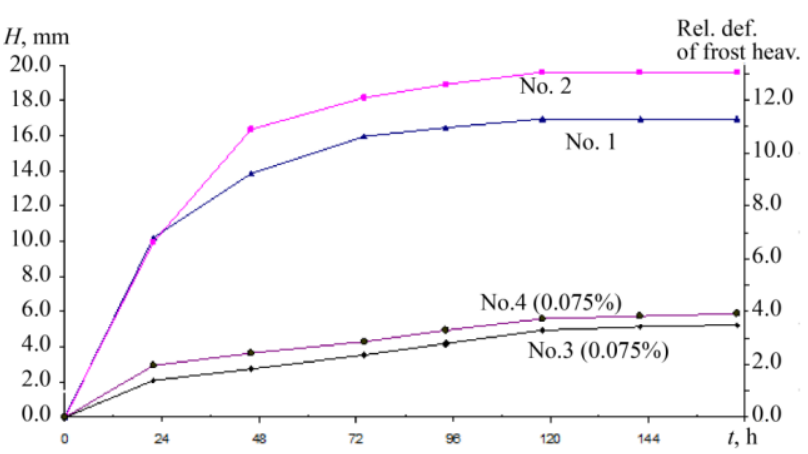

Fig. 5. The relationship between deformation of frost heaving and time for non-saline soil (samples Nos. 1\&2), and for soils with salinity of $0.075 \%$ (samples Nos. $3 \& 4$ ).

The obtained relative deformations of frost heaving of samples of the third stage and their classification according to the degree of frost heaving are shown in Table 1 .

Table 1.

\begin{tabular}{|c|c|c|c|c|}
\hline \multicolumn{2}{|c|}{ Soil type } & $\begin{array}{c}\varepsilon_{\mathrm{fn}}, \\
\%\end{array}$ & $\begin{array}{c}\varepsilon \text { fn av, } \\
\%\end{array}$ & $\begin{array}{c}\text { The degree of frost } \\
\text { heaving according to } \\
\text { the GOST 25100- } \\
2011\end{array}$ \\
\hline \multirow{4}{*}{$\begin{array}{l}\text { Reference } \\
\text { non-saline } \\
\text { soil }\end{array}$} & \multirow{2}{*}{ Sandy } & 1.73 & \multirow{2}{*}{1.85} & \multirow{2}{*}{ Slightly swollen } \\
\hline & & 1.97 & & \\
\hline & \multirow{2}{*}{ Clay } & 11.29 & \multirow{2}{*}{12.18} & \multirow{2}{*}{ Excessively swollen } \\
\hline & & 13.07 & & \\
\hline \multirow{4}{*}{$\begin{array}{c}\text { Soil with } \\
\text { salinity of } \\
0.15 \%\end{array}$} & \multirow{2}{*}{ Sandy } & 1.25 & \multirow{2}{*}{1.18} & \multirow{2}{*}{ Slightly swollen } \\
\hline & & 1.10 & & \\
\hline & \multirow{2}{*}{ Clay } & 4.28 & \multirow{2}{*}{4.00} & \multirow{2}{*}{ Moderately swollen } \\
\hline & & 3.71 & & \\
\hline \multirow{4}{*}{$\begin{array}{c}\text { Soil with } \\
\text { salinity of } \\
0.075 \%\end{array}$} & \multirow{2}{*}{ Sandy } & 0.99 & \multirow{2}{*}{1.47} & \multirow{2}{*}{ Slightly swollen } \\
\hline & & 1.95 & & \\
\hline & \multirow{2}{*}{ Clay } & 3.50 & \multirow{2}{*}{3.72} & \multirow{2}{*}{ Moderately swollen } \\
\hline & & 3,94 & & \\
\hline
\end{tabular}

The presented data shows that afort soil salinity values close to that which was established for clay soil of the roadbed on roads where anti-icing additives are used, the relative deformation of frost heaving $\left(\varepsilon_{\mathrm{fn}}\right)$ decreased by about 3.04 to 3.27 times.

When using the traditional technology of applying anti-icing additives to the road surface, there is no certainty that the salinity of the roadbed will be constant. This is primarily due to the use of sand-salt mixtures, since due to the diffusion of salts, local salinization of certain sections of the roadbed will occur. The uneven salinity of the roadbed soil body will cause uneven deformation of the road surface caused by frost heaving. These deformations can lead to a violation of the frost resistance of the road structure, even if it was provided by the calculation for non-saline soil.

It should be noted that in order to solve the problem associated with the influence of anti-icing additives on the frost resistance of the road structure, the study must be continued in the following directions:

1. Revealing the relationship between the type of additive and the method of applying it to the road surface and the value and unevenness of the salinity of the roadbed soil; 
2. Determination of the characteristics of frost heaving for all types of clay soils for salinity caused by the use of anti-icing additives;

3. Determination of soil salinity at the stage of engineering and geological surveys during the reconstruction and repair of highways;

To recommend new chemical reagents as anti-icing additives, it is necessary to have the results of experimental determinations of their influence on the heaving properties of soil.

\section{Conclusions}

The obtained results allow us to conclude:

1. For soil samples taken from the body of the roadbed, which was treated with sodium chloride antiicing additives for a number of years, the determined salinity was in the range from 0.02 to $0.2 \%$. Comparative studies made for a soil sample with a salinity of $0.06 \%$ and a desalinated sample, showed that the relative deformation decreased by 2.3 times. The degree of frost heaving changed from excessively swollen to moderately swollen.

2. Test for frost heaving of the reference clay soil with salinity close to that found in the body of the roadbed for the surveyed section of the road showed that the influence of salinity on frost heaving is similar to that specified in paragraph 1 .

3 . The performed studies show that when using antiicing additives, frost resistance of the road structure can be ensured if the salinity of the roadbed soil is constant. If the salinity of the roadbed soil changes both in plan and in depth, as is obviously the case on real objects, an excess of the maximum deformation for the road surface may be observed, even if frost resistance of the road structure for non-saline soil is provided by calculation.

4. When using new chemical reagents as anti-icing additives, tests should be carried out to determine their influence on the heaving properties of soil. Some of these chemicals can cause an increase in the degree of frost heaving of soil.

\section{References}

1. X. Lai, H. Xu, P. Shan, Y. Kang, Z. Wang, X. Wu, Research on mechanism and control of floor heave of mining-influenced roadway in top coal caving working face, Energies 13 (2020)

2. D. Strelnikov, O. Khalimov, Experience in designing and operating the buildings located on subsiding and heaving soils of the Minusinsk Hollows, E3S Web of Conferences (2019)

3. N. Cherednichenko, P. Oleinik, Methods of erection of high-rise buildings, E3S Web of Conferences (2018)

4. A.J. Puppala, R. Kadam, R.S. Madhyannapu, L.R. Hoyos, Small-strain shear moduli of chemically stabilized sulfate-bearing cohesive soils, J. Geotech. Geoenvironmental Eng. (2006)
5. I. Fomenko, D. Shubina, D. Gorobtsov, O. Sirotkina $\mathrm{O}$, Thawing of permafrost soils under the water intake facility (the Taas-Yurekh river, Yakutia, Russia), E3S Web Conf., 140 (2019)

6. S. Chernyy, M. Järn, K. Shimizu, A. Swerin, S.U. Pedersen, K. Daasbjerg, L. Makkonen, P. Claesson, J. Iruthayaraj, Superhydrophilic polyelectrolyte brush layers with imparted anti-icing properties: Effect of counter ions ACS Applied Materials and Interfaces (2014)

7. S.B. Ukhov, On artificial salinization of loamy soils for construction in winter News High. Educ. institutions. Constr., 1, 1 (1959)

8. Anon 2011 The Russian state Standard GOST 25100-2011. Soils. Classification. Introduced 07/01/11 (Moscow)

9. G.L. Kagan, V.A. Shorin, A.Y. Velsovskij, Effective Design Solutions in the Design of Shallow Foundations, IOP Conf. Ser. Mater. Sci. Eng., 463, 22073 (2018)

10. G.L. Kagan, V.A. Shorin, A.Y. Velsovskij, To the question of improvement the normative methodology for calculating the frost resistance of a road structure, E3S Web Conf., 161, 1038 (2020)

11. A. Vel'sovskij, B. Karpov, E. Smirnova, Development of a new method for checking frost heave in roads Proc. Inst. Civ. Eng. - Civ. Eng., 168, 49-54 (2015)

12. V.A. Shorin, G. Kagan, A.Y. Velesovskii, A new diagnostic instrument and method for stabilization of heaving soil in the beds of structures, Soil Mech. Found. Eng., 45, 144-147 (2008)

13. V.A. Shorin, G.L. Kagan, A.Y. Vel'sovskii, Reliability of indirect methods for evaluation of the heaving properties of soils, Soil Mech. Found. Eng., 49, 111-114 (2012)

14. G.L. Kagan, L.R. Mukhametova, A. Y. Velsovskij, A method for construction of an energy-efficient ice floating pier in the Arctic using hardened ice, E3S Web Conf., 178, 1064 (2020)

15. V.A. Shorin, G.L. Kagan, A.Y. Velsovsky, Patent RU 2319145 C1 IPC G01N33/38. Autonomous device for testing soil for frost heaving. Published 10.03.2008 bull. 7 (2008)

16. D. Mazhitov, M. Ermilova, E. Altukhova, T. Maksimova, and O. Zhdanova, Development of Technologies and Processes in Environmental Management, E3S Web of Conferences 135, 04045 (2019). doi:10.1051/e3sconf/201913504045.

17. J.G. Bazarnova, N. A. Politayeva, and S. G. Bozhuk, Innovative Technologies Secondary use of Processed Active Source, Proceedings of the 2017 International Conference "Quality Management, Transport and Information Security, Information Technologies", IT and QM and IS 2017, 8085865, 471-476 (2017). doi:10.1109/ITMQIS.2017.8085865 